\title{
KURDISH EFL LEARNERS' CONCEPTUAL TRANSFER IN L2 WRITING
}

\author{
JAMAL ALI OMAR \\ Faculty of Basic Education, University of Raparin \\ Ranya/Al-Sulaymaneyah, Iraq \\ E-mail address: jamal.ali@uor.edu.krd
}

\begin{abstract}
The phenomenon of language transfer in SL learning and use is perennial and cannot be silenced easily. In L2 writing, the phenomenon is found to affect the written products to become nonnative and be ambiguous. It is thought that the transfer occurs at the conceptual and structural level of language use. The present paper examines Kurdish EFL learners' writing aiming at identifying transfer types, particularly, the negative transfer. To this end, 20 university level English major students' argumentative writing are analyzed focusing on the conjuncts and adjuncts to find out any track of L1 concepts. The logical clause relationship of cause-effect was the area of focus. The results of the study showed that L1 concepts have been used in forming the relations between sentences and clauses spelt out by lexical signals of sentence connectors and subordinators. It was also found that L1 concepts were transferred into L2 writing. The insights gained from the results of the study reveal that there is a problem, especially the negative influence of $\mathrm{L} 1$, which needs to be attended to.
\end{abstract}

Key words: Conceptual Transfer, L2 writing, Negative Transfer

\section{INTRODUCTION}

The influence of the first language in learning and use of another language has long been the area of concern for Second Language Acquisition (SLA) researchers, Applied Linguists and language educators (Odlin, 1989, 2016; Jarvis, 2007, 2012, 2016; Jarvis, \& Pavlenko, 2008). The influence, which is known as Language Transfer (LT) or Cross Linguistic Influence (CLI), refers to the role of the native language (source language) in learning and use of another language (recipient language), be it negative or positive. Researchers in the field of language acquisition confirmed that LT occurs across all the linguistic levels. Crossley and McNamara (2012, p. 107) stated that "Past research has demonstrated that CLI affects almost all areas of linguistic and communicative competence including the lexicon, syntactic constructions, text cohesion and conceptual knowledge. Studies confirmed that some independent variables affect LT. Among these variables are learners' language level, age, learning context, the similarities and differences 
found between the structural properties of the source and recipient languages, etc". (Jarvis, \& Pavlenko, 2008). The influence is found to have different manifestations among which the dichotomous negative or positive transfer are the most common types thereof. Other manifestations of CLI include underuse and overuse of the target language structures and forms. It is also verified that the effect can be forward or backward, i.e. bidirectional transfer.

L1 influence in L2 writing occurs within the various areas of grammar, composing, organization, coherence and cohesion and rhetoric. Transfer in L2 writing is considered a learning tool and a strategy to solve communication problems (Karim, \& Nassaji, 2013). In the conclusion of their study, Karim and Nassaji (2013) confirmed that, based on earlier empirical studies, various areas and variables of L1 transfer in L2 writing were attended and, consequently, both negative and positive types of transfer were verified. However, L1 conceptual transfer in L2 writing is understudied, particularly in the case of Kurdish EFL learners. To bridge this gap, the current study attends to conceptual transfer in L2 writing. The primary focus will be on forward conceptual transfer in Kurdish EFL learners' writing, which falls within the area of text organization in which the cause-effect structure with its signaling vocabularies will be prioritized. Accordingly, in the following sections the background and previous studies related to the focused type of transfer and area are presented.

\section{BACKGROUND OF THE STUDY}

This study falls within the area of CLI which is a prominent phenomenon and factor in SLA. CLI or LT refers to the influence of previously acquired language knowledge on learning and use of another language. The influence can, similarly to the other areas: semantic, phonology, syntax, etc., occur at a conceptual level which is known as conceptual transfer. Conceptual transfer is defined and discussed differently. For example, Jarvis and Pavlenko (2008, p. 115) define it as "the effects of one language on the verbalization of thoughts in another." As a theoretical construct, Jarvis $(2007$, p. 44) states that conceptual transfer "can be characterized as the hypothesis that certain instances of crosslinguistic influence in a person's use of one language originate from the conceptual knowledge and patterns of thought that the person has acquired as a speaker of another language." In case of a Finn when using the word jar to refer to a tin can, the influence from Finnish is likely to be largely conceptual "because Finnish speakers seem to mentally categorize jars and cans as being members of the same category regardless of whether they are made out of glass, porcelain, plastic, or metal," Jarvis and Pavlenko (2008, p. 76).

The theoretical development of conceptual transfer started with the interplay between language, culture and thought which has long been the area of focus for researchers with both a monolingual and second/foreign language users' perspective. In the latter context, as the earliest attempts to attend to conceptual transfer in L2 writing, the focus was on "the way in which the lear- 
ner organizes his utterances is heavily influenced by the conceptual structure present in the source language" (von Stutterheim, \& Klein, 1987, p. 196). Additionally, conceptual studies maintain that EFL learners' conceptual system is a mixed system of L1-based, L2-based and shared concepts. "Indeed, some recent work on conceptual transfer indicates that even highly proficient learners may never free themselves entirely of the "binding power" of L1" (Odlin, 2005). This is so as the deeply entrenched concepts and thoughts of L1 remain to be retrieved easily in EFL learners' mind. Similarly, the learned conceptual system of the foreign language is also substantial for writing in the foreign language. EFL learners' cognitive system has two conceptual systems of L1 and FL that contribute in L2 writing. The contribution of the two systems might not be favorable, especially with different conceptually language-specific utterances. Hence, the learners, unlike writing in their L1, have various concepts to recourse to while writing in L2. This is particularly true with the different conceptual relationships of time and place cross-linguistically. In other words, different conceptions on how to refer to an event, idea, location, time, etc. across languages have created the ground for conceptual transfer to occur. Furthermore, various studies have shown that CLI is affected by differences in language-mediated concepts and language specific patterns (Crossley, \& McNamara, 2012, p. 113). Sharpen (2016) also carried out a study using inverse translation tasks by English native speaker learners of Spanish and Spanish native speaker learners of English focusing on motion events. In the study the basis for exploring the notion of conceptual transfer is Slobin's (1987) thinking-for-speaking hypothesis. Jarvis and Pavlenko (2008, pp. 122-148) also reviewed a group of studies for eight conceptual domains: objects, emotions, personhood, gender, number, time, space and motion for which lexicalized and grammatical concepts were represented. For each domain, empirical evidence was provided. Kobayashi and Rinnert (2008) carried out an exploratory study on 28 Japanese university students to assess the influence of intensive high school training in L1 and L2 essay writing. The findings provided evidence of CLI of writing competence across languages, i.e. bidirectional transfer. In their study, the researchers insisted that writing and text construction can be influenced by many factors of social, contextual, cultural variables as well as previous writing experience and instruction. Among these variables, the L1 conceptual knowledge can be transferred and projected onto L2 writing. It is obvious that most of the transfer cases resulted from "differences in conceptual categories corresponding to lexical and grammatical categories of the source and recipient languages" (Jarvis, \& Pavlenko, 2008, p. 112). Or the differences which cause transfer "in relation to the mental concepts that underlie those forms and structures." In particular, the conceptual categories of the common text structures found in English language for organizing texts and maintaining coherence, such as cause-effect, contrasting information, sequencing the events, etc. These are represented by using the conjunctions and subordinate words and phrases in English texts; for example, 'because' for cause-effect, 'but' for contrasting information. The question is to what extent KLEs' use of the coherence structures in L2 writing 
is influenced by L1? Does the influence have a positive or negative effect? The aim of the present study is to identify cases of conceptual CLI in KLEs' L2 writing. Thus the study strives to answer these questions and achieve the stated aim of identifying the forward type of conceptual transfer.

\section{RESEARCH METHOD}

\section{Participants}

In the study, data was collected from 52 participants: three different groups of Kurdish ${ }^{1}$ Learners of English (KLEs) (20), Kurdish Native Speakers (KNSs) (16) and English Native Speakers (ENSs) (16). All the participants were senior university students. The average of their age was 22 . They voluntarily participated in the study. The first two groups, who were studying in public universities of University of Raparin, Koya University and University of Sulaymaneyah in Kurdistan Region ${ }^{2}$ in the north of Iraq, were Kurdish native speakers. The participants in the last group were studying in Virginia Polytechnic and State University in Virginia/USA. KLEs represented the focus group in the study while the two other groups represented the baseline groups to which the first group's written performance was compared to find out similarities and differences.

\section{The Approach}

The approach used based on the degree of resemblance found between KLEs' text structures and their signals with those of the two baseline groups of ENSs and KNSs. The focus of the analysis was on the conjuncts and adjuncts in those texts, which were considered signals for the organization structure in which the relevant concepts of L1 might have influenced L2 writing. These were represented by common structures of text organization such as cause-effect. The parameter was that when KLEs' structure and the signaling vocabularies resembled both ENS and KNS accounts for positive transfer. However, if KLEs' structure and the signaling vocabularies resemble KNS but different from ENS, it amounts to negative transfer. Finally, if KLEs' structure and the signaling vocabularies resemble ENS but were different from KNS, it amounts to neutral transfer.

\section{Procedures}

The process of data collection was to ask KLEs to write an opinion article in response to the prompt "Some people believe that when parents make their

1 Kurdish Language is from the Iranian branch of the Indo-European languages. It has around thirty million speakers distributed among the countries of Turkey, Syria, Iraq and Iran. The language has three major dialects of northern (Kurmanji), middle (Sorani) and southern (Hawrami). The first dialect has the largest number of speakers in Turkey and Syria, the middle dialect is spoken in northern Iraq and western Iran, the southern dialect is spoken in middle western of Iran and middle eastern of Iraq.

2 The current study is limited with the Sorani dialect of Kurdish language, thus, its implication and generalization is only applicable to the speakers of that dialect. 
children's lives too easy, they can actually harm their children instead." The same procedure was conducted with both ENSs and KNSs. In the case of the latter group, the prompt was translated into Kurdish language because they were required to write in Kurdish. The purpose behind collecting data from English and Kurdish native speakers was to compare the data by KLEs to find the degree of resemblance.

The analysis of the written articles began with numbering each of the sentences and searching for each of the forms of text organization by focusing on the signals that represent the forms. For example, in the excerpt "sometimes your children need to advice particularly on the beginning of their ages because at that time they are too young to depend on their lives and doing everything by themselves" the signals "because' depicts the organization structure cause-effect. The same procedures carried out with the articles written by the baseline groups. The aim is to sort out the text structures of the participant groups. In the second stage, the common identified structures of the focus group were compared and contrasted with those of the baseline groups to find out similarities and differences. The below excerpts and sentences are a few representative examples of the text structures and their signaling vocabularies taken from KLEs, KNSs and ENSs. The signaling vocabularies were written in bold to represent the text structure cause-effect. They were chosen to showcase the presence of the structure and its various signaling vocabularies in the participant articles. As it is found in the excerpts below, the groups share signaling vocabularies to realize cause-effect text structure. It is also found that there were group-specific signals to realize the structure. Details are provided in the results section below.

1. Quotes from KLE texts that are examples for the cause effect text structure: "when you make their life too easy so there aren't any chance for children to try, to work, to make decision about their life".

"When parents [make] the life of their children too easy then they harm them".

"If parents do every Thing for Their child, so Their child what should does for them self".

"If children don't encounter difficulty, in the future they can't solve their problem in their life".

2. Quotes from KNS texts that correspond to the word signals for the cause-effect text structure:

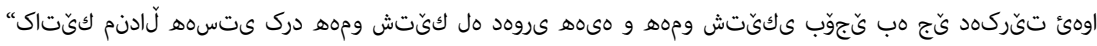

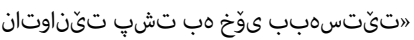

"when child felt everything is around him/her and everything will be done for him/ her then he/she cannot depend (rely) on him/herself" or cannot be self-dependent".

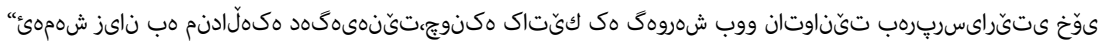

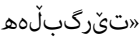

"This causes the child harm (brings harm to the child), because when he/she grew up he/she cannot keep personal liability" "or bear responsibility".

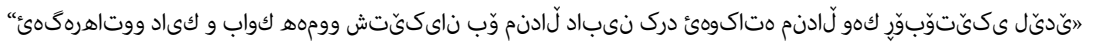


Quotes from ENS texts that correspond to the word signals for the cause-effect text structure:

"To correlate with the examples above, this could mean that the parent does not impose discipline on their child when they have misbehaved".

"If a college student still has someone else handle these tasks, then when will the student learn to take the initiative and learn?".

"They both grew up in stable homes, and therefore, they provided me with a stable home".

\section{Results}

Results obtained show that there were both similarities and differences in the type of signal used to realize cause-effect text structure used in the participants' texts. With regard to the similarities, it is found that the three group participants share the signals 'when', 'if', 'because' and 'so' to realize the text structure. Additionally, the groups share the correlative pair 'if ... then' to realize the structure. However, KLEs' use of the correlative pairs "when ... then/so/at that time/in the future" and "If ... then/so/at that time/in the future" was similar to KNSs' realization of the effect element of the structure but different from ENSs structure realization. The table below illustrates the group participants' realization of cause-effect text structure through various signaling vocabularies.

Table 1. The three group participants realization of Cause-Effect

\begin{tabular}{|c|c|c|}
\hline ENS & KNS & KLE \\
\hline when & $\begin{array}{c}\text { When ... then/in the future/ } \\
\text { at that time }\end{array}$ & $\begin{array}{l}\text { When, when ... then/so/at } \\
\text { that time/ in the future }\end{array}$ \\
\hline If, If ... then & If $\ldots$ then/at that time & $\begin{array}{c}\text { If, If ... so/at that time/in the } \\
\text { future }\end{array}$ \\
\hline $\begin{array}{l}\text { because } \\
\text { since }\end{array}$ & $\begin{array}{l}\text { Because } \\
\text { Cause (v.) }\end{array}$ & Because \\
\hline Therefore & Caused by & \\
\hline In order to & In order to & \\
\hline Thus & Thus & \\
\hline \multicolumn{3}{|l|}{ Due to } \\
\hline As a result & As a result & \\
\hline So & So & So \\
\hline
\end{tabular}

\section{DISCUSSION, CONCLUSION AND IMPLICATION OF THE STUDY}

Based on the results obtained, KLE participants, the focus group in the study had less options to realize the text structure than ENS and KNS groups - the two baseline groups in the study. KLEs' realization of the text structure by the limited number of signaling vocabularies (see the table above) 
amounts to various reasons among which lack of TL knowledge and conceptual transfer. The former was evidenced in the limited use of the signals, compared with the baseline groups, to realize the structure. The latter was evidenced by transferring of the correlative pairs common in L1 but not found in L2. To elaborate it, KLEs' use of the signals 'when ... then/at that time/in the future', which are considered the translation equivalent for 'كئتاك

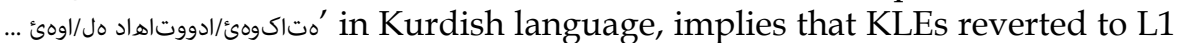
conceptual knowledge and system. In other words, the way the future effect of the cause signaled by 'when' was influenced by L1 temporal notion as it couldn't be found in TL. Hence, temporal notions of L1 have been projected onto L2 writing by KLEs. As a result, that projection might lead to production of a type of text that is not common in L2 writing, and it might cause miscommunication or ambiguity. Similarly, the way the conditional relation was realized by the correlative pair vocabularies 'if ... so/in the future/at

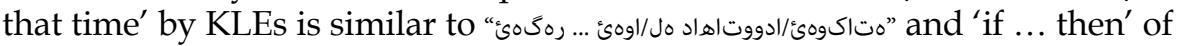
both the baseline groups. Nevertheless, the way KLEs realized the structure through the correlative pair 'if ... at that time/in the future' is similar to KNS group amounts to their L1 conceptual knowledge besides. The basic notion of conditional structure of L1 was used in forming the text structure. Nonetheless, KLEs' use of the conditional 'if' separately was similar to ENSs as that was not found in KNSs' realization of the structure. The projection of L1 conceptual knowledge onto L2 writing is present which might cause ambiguity and miscommunication. Hence, negative and positive types of transfer occurred in KLEs' L2 writing.

In addition to negative and positive types of transfer, learners' overuse of the signals 'when', 'because', 'if' and 'so' and underuse of other signals common in the baseline groups originated from lack of TL knowledge and influence from L1. The latter, in particular, was clearly evidenced by KLEs' favoring of certain signals common in their L1 over other signals common in L2. In other words, learners' recourse to text structure signals common in L1 implies that in their learning context, with the limited chance of TL practice and use, their L1 conceptual system is prevalent in their mind to which conceptual knowledge was easily retrievable to L2 knowledge. Hence, the problem occurs if the knowledge learners reverted to was different which might cause communication breakdown due to negatively transferring L1 knowledge into L2 writing.

Apart from the different manifestations of transfer, analyzing the writings of the group participants, it was observed that a fundamental difference is apparently occurred in ENS and KNS articles. The difference was in the use of personal experience by ENS writers as a persuasive writing strategy, however, it did not occur in KNS writing. The focus group writers, in turn, influenced by their L1 conceptual system, cultural and instructional background, never revert to that strategy when writing in L2. In the excerpts below, which are by ENS writers, the case above is illustrated: 
"When I was young, my mom would give my sister and I chores for each week. On Sunday night, she would give us a list of things we needed to complete by the following Sunday". (ENS)

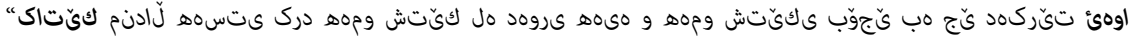
"

"when child felt everything is around him/her and everything will be done for him/her then he/she cannot depend (rely) on him/herself" or cannot be self-dependent". (KNS)

"when the parents assist their children too much, there is not any doubt the children will be very uncomfortable in the future". (KLE)

In conclusion, results showed that conceptual transfer was found in Kurdish EFL learners' argumentative writing in English. The type of transfer was based on the degree of resemblance of the text building techniques those learners used compared with ENSs and KNSs techniques and strategies of text building. It is clear that KLEs conceptually referred to the same text construction strategies in different ways and in ways that are similar to their native language. This is verified by the similarities and congruence found between those learners' text construction strategies in L1 and L2 writing. The techniques and strategies found in their L2 writing represent conceptual knowledge that was not present in the TL writing. Thus, cases of conceptual transfer were identified in Kurdish EFL learners' L2 writing. Nevertheless, the question is what type of transfer does occur in those learners' writing performance? In case of similarities among all the participant groups text structure, the type of transfer is positive. However, differences between the focus group with TL but similar with L1 makes the transfer type be negative which might have unfavorable consequences. Other manifestations of transfer was the underuse of signals which were common in TL, and overuse of certain signals which were common in L1. In addition to the role of L1 in L2 writing, lack of TL knowledge was also concluded to be one of the reasons for negative transfer and underuse of some signals. This issue can be settled if two or more proficiency level language learner groups are tested and their written texts analyzed. Hence, the current study recommends that language proficiency as a dependent variable can play a great role and it can make a promising area for researchers to be studied. Another recommendation obtained from the results of the present study is that more languages can be incorporated to find out what is unique about each language group. It can also find the extent to which their language background affect their performance in TL, be it written or spoken use of the language. Furthermore, interpretation of the results have pedagogical implications for EFL teachers and syllabus designers. The current study suggests that EFL teachers should do their best to make students be familiarized with the similarities and differences between L1 TL text structure signals; the former will facilitate while the latter will hinder the flow of L2 communication. Syllabus designers, in their part, should put special focus on those text structures that are more liable to be transferred by designing special exercises that can solve that problem. 


\section{APPENDIX: \\ SAMPLE ARTICLE WRITTEN BY KURDISH EFL LEARNER}

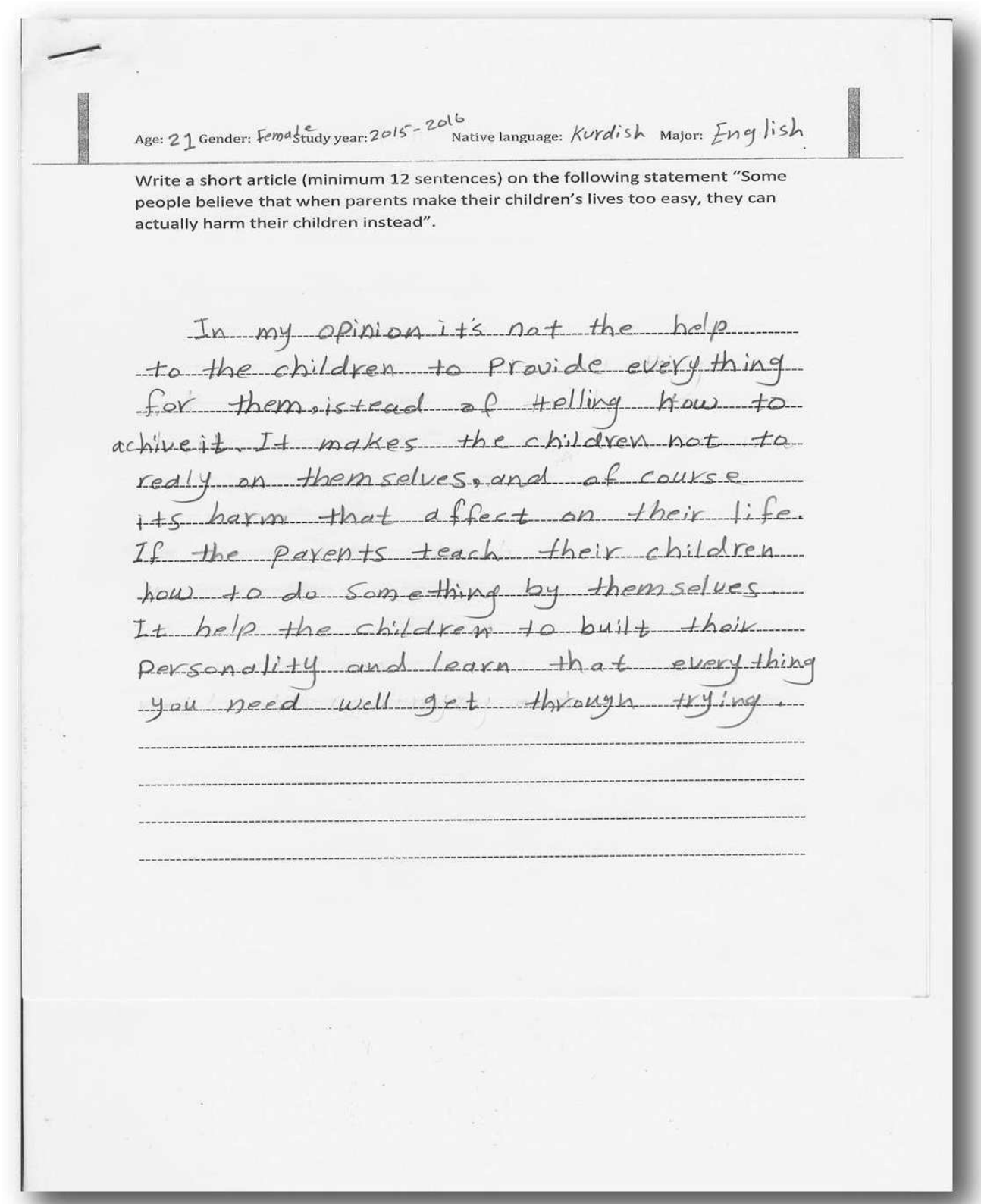




\section{REFERENCES}

1. Bagherian, A. (2012). EFL learners' L1 conceptual transfer and its relation to their language proficiency and age. International Journal of Applied Linguistics and English Literature, 1(4), 152160. doi:http:/ /dx.doi.org/10.7575/ijalel.v.1n.4p.152

2. Crossley, S. A., \& McNamara, D. S. (2012). Detecting the first language of second language writers using automated indices of cohesion, lexical sophistication, syntactic and conceptual knowledge. In S. Jarvis and S. Crossley (Eds.) Approaching language transfer through text classification: Explorations in the detection-based approach, pp. 106-126. Clevedon: Multilingual Matters.

3. Jarvis, S., \& Pavlenko, A. (2008). Crosslinguistic influence in language and cognition. New York, NY: Routledge.

4. Karim, Kh., \& Nassaji, H. (2013). First language transfer in second language writing: An examination of current research. Iranian Journal of Language Teaching Research 1(1), pp. 117- 134. Retrieved on 04/07/17 from http:/ / files.eric.ed.gov/fulltext/EJ1127353.pdf

5. Kobayashi, H., \& Rinnert, C. (2008). Task response and text construction across L1 and L2 writing. Journal of Second Language Writing 17 (2008) 7-29. doi:10.1016/j.jslw.2007.08.004. Retrieved on 08/07/17 from http:/ / www.sciencedirect.com/

6. Odlin, T. (2005). Croslinguistic influence and conceptual transfer: what are the concepts? Annual Review of Applied Linguistics, 25, 3-25. doi:10.1017/S0267190505000012

7. Sharpen, R. (2016). L1 Conceptual Transfer in the Acquisition of L2 Motion Events in Spanish and English: The Thinking-for-Speaking Hypothesis. Open Linguistics, 2 (1), pp. 235-252. Retrieved on 26 Jun. 2017, from doi:10.1515/opli-2016-0011

8. Von Stutterheim, C., \& Klein, W. 1987. A concept-oriented approach to second language studies". In C. W. Pfaff (Ed.), First and second language acquisition processes (pp. 191-205). Cambridge, MA: Newbury House. 